\title{
Circadian time-dependent effects of fencamfamine on inhibition of dopamine uptake and release in rat striatal slices
}

\author{
R. DeLucia ${ }^{1}$, \\ C.S. Planeta ${ }^{2}$, \\ M.P. Ferreira ${ }^{1}$, \\ M.L. Aizenstein ${ }^{1}$ \\ and C. Scavone ${ }^{1}$
}

\author{
${ }^{1}$ Departamento de Farmacologia, Instituto de Ciências Biomédicas, \\ Universidade de São Paulo, 05508-900 São Paulo, SP, Brasil \\ 2Departamento de Princípios Ativos, Naturais e Toxicologia, \\ Faculdade de Ciências Farmacêuticas, Universidade Estadual Paulista, \\ 14801-902 Araraquara, SP, Brasil
}

\author{
Correspondence \\ R. DeLucia \\ Departamento de Farmacologia \\ Instituto de Ciências Biomédicas \\ Universidade de São Paulo \\ 05508-900 São Paulo, SP \\ Brasil \\ R. DeLucia, C.S. Planeta, \\ M.L. Aizenstein and C. Scavone are \\ recipients of CNPq fellowships. \\ Publication supported by FAPESP.
}

Received July 3, 1996 Accepted February 26, 1997

\begin{abstract}
Fencamfamine (FCF) is a central stimulant that facilitates central dopaminergic transmission through inhibition of dopamine uptake and enhanced release of the transmitter. We evaluated the changes in the inhibition of uptake and the release of striatal $\left[{ }^{3} \mathrm{H}\right]$-dopamine at 9:00 and 21:00 $\mathrm{h}$, times corresponding to maximal and minimal behavioral responses to FCF, respectively. Adult male Wistar rats (200-250 g) maintained on a 12-h light/12-h dark cycle (lights on at 7:00 h) were used. In the behavioral experiments the rats $(\mathrm{N}=8$ for each group) received FCF $(3.5 \mathrm{mg} / \mathrm{kg}$, ip $)$ or saline at 9:00 or 21:00 h. Fifteen minutes after treatment the duration of activity (sniffing, rearing and locomotion) was recorded for $120 \mathrm{~min}$. The basal motor activity was higher $(28.6 \pm 4.2$ vs $8.4 \pm 3.5 \mathrm{~s})$ after saline administration at 21:00 $\mathrm{h}$ than at 9:00 $\mathrm{h}$. FCF at a single dose significantly enhanced the basal motor activity $(38.3 \pm 4.5$ vs $8.4 \pm 3.5 \mathrm{~s})$ and increased the duration of exploratory activity $(38.3 \pm 4.5 \mathrm{vs} 32.1 \pm 4.6$ s) during the light, but not the dark phase. Two other groups of rats ( $N$ $=6$ for each group) were decapitated at 9:00 and 21:00 h and striata were dissected for dopamine uptake and release assays. The inhibition of uptake and release of $\left[{ }^{3} \mathrm{H}\right]$-dopamine were higher at 9:00 than at 21:00 h, suggesting that uptake inhibition and the release properties of FCF undergo daily variation. These data suggest that the circadian time-dependent effects of FCF might be related to a higher susceptibility of dopamine presynaptic terminals to the action of FCF during the light phase which corresponds to the rats' resting period.
\end{abstract}

Fencamfamine $(\mathrm{FCF})$ is a central stimulant classified as an indirect dopaminergic agonist, that facilitates dopaminergic transmission in the central nervous system through blockade of dopamine uptake and enhanced release of the neurotransmitter (1). In vitro, FCF blocks the inhibition of $\left[{ }^{3} \mathrm{H}\right]$-dopamine uptake in brain synapses with a potency similar to that of amphetamine, while the $\left[{ }^{3} \mathrm{H}\right]-$ dopamine releasing activity in striatal slices
Key words

- Fencamfamine

- Chronopharmacology

- Behavior

- Dopamine uptake

- Dopamine release 
among athletes (6) and students (7).

Recently, we demonstrated that the behavioral and neurochemical effects of FCF in rats were circadian time dependent (8). Compared to saline-treated animals, the increase in sniffing, rearing and locomotion duration and in the striatal level of the major dopamine metabolite, homovanillic acid (HVA), induced by FCF was higher during the light phase, suggesting a higher susceptibility to FCF during the resting phase of the animals. In addition, we reported that plasma FCF levels and dopamine receptors undergo daily variation, a phenomenon that should be considered to explain the circadian timedependent effects of FCF (9). However, conclusive studies explaining the mechanisms of the circardian time-dependent effects of FCF remain to be performed.

In order to better characterize the mechanisms underlying the circadian time-dependent effects of FCF, in the present study we determined changes in the inhibition of uptake and in the release of striatal dopamine at times corresponding to maximal or minimal behavioral responses to FCF.

Forty-four rats were used in behavioral and uptake and release experiments. Animals were housed in plastic cages $32 \mathrm{x} 40 \mathrm{x}$ $16 \mathrm{~cm}$ (width $\mathrm{x}$ length $\mathrm{x}$ height) in a room maintained at $22 \pm 1^{\circ} \mathrm{C}$ and illuminated by white lights at 100 lux. The animals were maintained under a 12:12-h light/dark (LD) regimen, lights on from 7:00 to 19:00 h, for 9 weeks before the experiments. Food and water were available ad libitum. When the animals were 3 months old and weighed 200-250 g they were used in the experiments.

Seven days before the experiments the animals were individually housed in wire mesh cages $15 \times 30 \times 19 \mathrm{~cm}$ (width $\times$ length $\mathrm{x}$ height) with continuous access to food and water except during the observation period.

Thirty-two animals were randomly assigned to four groups of 8 rats each. The animals were injected intraperitoneally $(i p)$ with either saline or FCF $(3.5 \mathrm{mg} / \mathrm{kg})$, ac- cording to a procedure described previously (8). Each group was injected at one of two times, 9:00 and 21:00 $\mathrm{h}$, and $15 \mathrm{~min}$ after treatment their behavior was measured for $120 \mathrm{~min}$ to collect activity data (sniffing + locomotion + rearing). Each animal was observed for $60 \mathrm{~s}$ at successive 15-min intervals, either under white (light period) or red light (dark period). During the 60 -s observation periods the duration in seconds was recorded by direct entry into a microcomputer from one keyboard terminal. The observer was not aware of the treatments and was the same for all observations.

Twelve animals were divided into two groups $(\mathrm{N}=6)$. Animals were decapitated at 9:00 or 21:00 $\mathrm{h}$ and the brains were rapidly removed and used for the uptake and release experiments. Striatal slices were incubated at $37^{\circ} \mathrm{C}$ for 60 min with Krebs-Ringer buffer, $\mathrm{pH} 7.4$, and $1 \mu \mathrm{M}$ ascorbic acid. Triplicate series of incubation tubes received $0.1 \mu \mathrm{M}$ $\left[{ }^{3} \mathrm{H}\right]$-dopamine and striatal slices. The tubes were incubated at $37^{\circ} \mathrm{C}$ for $5 \mathrm{~min}$, and then rapidly filtered under vacuum through Whatman GF/B filters. The filters were rinsed with $5 \mathrm{ml}$ of cold assay buffer, and subsequently counted by liquid scintillation spectrometry in $5 \mathrm{ml}$ of EcoLume solution (ICN Biomedicals, Aurora, OH). FCF dissolved in distilled water at concentrations of 0.1-100 $\mu \mathrm{M}$ was tested as inhibitor of $\left[{ }^{3} \mathrm{H}\right]$-dopamine uptake according to the procedures described above. The $\mathrm{IC}_{50}$ values were obtained from semilogarithmic plots of the dose-response curve determined from FCF inhibition of dopamine uptake. In the release experiments, the radioactive medium was removed after uptake incubations and the slices were washed 7 times with $200 \mu \mathrm{l}$ of buffer and then incubated at $37^{\circ} \mathrm{C}$ for an additional 15 $\min$ in the assay buffer. The slices were exposed to various concentrations of FCF for $5 \mathrm{~min}$ at $37^{\circ} \mathrm{C}$. After centrifugation, the supernatants were transferred to a scintillation vial and assayed for radioactivity in $5 \mathrm{ml}$ of EcoLume at a counting efficiency of $37 \%$. 
Table 1 - Effects of fencamfamine on the behavioral response of rats.

Animals ( $N=8$ rats per group) received saline or FCF (3.5 mg/kg, ip, single dose) at 9:00 or 21:00 h. The duration of activity (s) was recorded for $2 \mathrm{~h}$ at 15 -min intervals. Data are reported as mean \pm SEM. ${ }^{*} P<0.01$, saline vs saline; $+P<0.01, F C F$ vs saline (Student $t$-test).

\begin{tabular}{lcc}
\hline \multirow{2}{*}{ Treatment } & \multicolumn{2}{c}{ Duration of activity (s) } \\
\cline { 2 - 3 } & \multicolumn{1}{c}{$9: 00$} & $21: 00$ \\
\hline Saline & $8.4 \pm 3.5$ & $28.6 \pm 4.2^{*}$ \\
Fencamfamine & $38.3 \pm 4.5^{+}$ & $32.1 \pm 4.6$
\end{tabular}

Stimulated release is the release occurring in the presence of FCF minus the background release. Results are reported as the amount of $\left[{ }^{3} \mathrm{H}\right]$-dopamine released (stimulated release/total slice content x 100\%).

As shown in Table 1, the basal motor activity was significantly $(\mathrm{P}<0.01$, Student $t$ test) higher after saline injection at 21:00 h, indicating the nocturnal pattern of activity of rats. FCF at a single dose significantly ( $\mathrm{P}<0.01$, Student $t$-test) enhanced the basal motor activity and increased the duration of exploratory activity by approximately $20 \%$ during the light, but not during the dark phase. These data suggest a higher susceptibility to FCF during the resting phase.

The uptake of $\left[{ }^{3} \mathrm{H}\right]$-dopamine at a concentration of $100 \mathrm{nM}$ into striatal slices was significantly inhibited in a dose-dependent fashion by all concentrations of $\mathrm{FCF}(\mathrm{P}<0.05$, Student $t$-test) (Table 2). The $\mathrm{IC}_{50}$ values of FCF were $1 \mu \mathrm{M}$ and $5 \mu \mathrm{M}$, at 9:00 and 21:00 $\mathrm{h}$, respectively.

Table 2 also summarizes the results of the release experiments. The release of $\left[{ }^{3} \mathrm{H}\right]-$ dopamine induced by FCF at various concentrations was significantly higher at $9.00 \mathrm{~h}$ than at $21.00 \mathrm{~h}(\mathrm{P}<0.05$, Student $t$-test $)$.

As reported previously (8) and in the present study, FCF-induced behavioral and neurochemical effects were higher following its administration during the light period,
Table 2 - Light-dark phase changes in the inhibition of uptake and the release of $\left[{ }^{3} \mathrm{H}\right]$ dopamine in striatal slices.

Data are reported as mean \pm SEM for six triplicate experiments. Inhibition of uptake and release of dopamine were induced by various concentrations of fencamfamine. ${ }^{*} \mathrm{P}<0.05$ (9:00 vs 21:00 h) (Student $t$-test).

\begin{tabular}{lrrrccc}
\hline \multirow{2}{*}{ Fencamfamine $(\mu \mathrm{M})$} & \multicolumn{2}{c}{ Inhibition of uptake $(\%)$} & & \multicolumn{2}{c}{$\left[{ }^{3} \mathrm{H}\right]$-dopamine release $(\%)$} \\
\cline { 2 - 3 } \cline { 6 - 7 } & $9: 00$ & $21: 00$ & & $9: 00$ & $21: 00$ \\
\hline 100 & $98.4 \pm 12.3^{*}$ & $81.5 \pm 11.2$ & & $3.83 \pm 0.75^{*}$ & $2.55 \pm 0.57$ \\
10 & $56.1 \pm 9.7^{*}$ & $39.5 \pm 8.7$ & & $1.03 \pm 0.31^{*}$ & $0.51 \pm 0.22$ \\
1.0 & $35.1 \pm 9.5$ & $27.4 \pm 5.7$ & & $0.10 \pm 0.02^{*}$ & $0.04 \pm 0.01$ \\
0.10 & $12.1 \pm 3.2^{*}$ & $2.5 \pm 0.6$ & & - & -
\end{tabular}

suggesting a higher susceptibility to the drug when administered during the resting phase. In fact, it has been demonstrated that the effects of dopamine agonists and antagonists undergo daily variation $(10,11)$. However, the mechanisms related to the circadian rhythmicity of the effects of these drugs have not yet been established.

Among others, release and uptake systems as well as receptor sensitivity all have their own rhythmic activity that may contribute to explaining the mechanisms of the circadian time-dependent effects of FCF. In line with this view we should consider lightdark phase changes occurring in the axonal terminals. Our results showed that inhibition of uptake and the release of striatal $\left[{ }^{3} \mathrm{H}\right]-$ dopamine induced by FCF are higher during the light period, suggesting the presence of daily variation in inhibition blockade uptake and release properties of FCF. Moreover, the findings of our release studies are in agreement with others showing that the release of $\left[{ }^{3} \mathrm{H}\right]$-dopamine from striatal synaptosomes induced by amphetamine or potassium was higher in tissues from animals killed during the light period (12). Our data suggest that the circadian time-dependent effects of FCF may be related to a higher susceptibility of dopamine presynaptic terminals to the actions of FCF during the resting phase of animals. 


\section{References}

1. DeLucia R \& Planeta CS (1990). Fencamfamine. General Pharmacology, 21: 161163.

2. Seyfried CA (1983). Dopamine uptake inhibiting versus dopamine releasing properties of fencamfamine: an in vitro study. Biochemical Pharmacology, 32: 23292331.

3. Kuczenski R, Segal $D$ \& Aizenstein $M L$ (1991). Amphetamine, cocaine, and fencamfamine: Relationship between locomotor and stereotype response profiles and caudate and accumbens dopamine dynamics. Journal of Neuroscience, 11: 2703-2712.

4. Aizenstein ML, Scavone C, Bernardi MM \& DeLucia R (1983). Comparative biochemical and behavioral effects of fencamfamine and d-l-amphetamine in rats. Progress in Neuro-Psychopharmacology and Biological Psychiatry, 7: 187-194.

5. Aizenstein ML, Planeta CS, DeLucia R \& da Silva CRS (1995). Effect of apomorphine on rat motor activity induced by fencamfamine and other indirect psychostimulant drugs. Brazilian Journal of Medical and Biological Research, 28: 667-670.
6. Delbeke FT \& Debackere M (1981). Detection and metabolism of fencamfamine and the influence of acetazolamide on its urinary excretion. Biopharmaceutics and Drug Disposition, 2: 17-30.

7. DeLucia R \& Planeta CS (1989). Padrões de uso de psicoestimulantes e energizantes por universitários: análise do período 1983-1988. Revista da Associação Brasileira de Psiquiatria - Associação de Psiquiatria da América Latina, 11: 111-113.

8. Planeta CS, Aizenstein ML, Scavone C \& DeLucia R (1989). Behavioral and neurochemical effects of fencamfamine on rats: a chronobiologic approach. Chronobiology International, 6: 313-320.

9. Planeta CS, DeLucia R, Aizenstein ML \& Oliveira GH (1994). Daily variation in plasma concentration of fencamfamine and striatal dopamine receptors in rats. Brazilian Journal of Medical and Biological Research, 27: 737-741.
10. Kuribara H \& Takadoro S (1982). Circadian variation in methamphetamine and apomorphine-induced increase in ambulatory activity in mice. Pharmacology, Biochemistry and Behavior, 17: 1251-1256.

11. Campbell A, Herschel M, Sommer B, Madsen JR, Cohen BM \& Baldessarini RJ (1982). Circadian changes in the distribution and effects of haloperidol in the rat. Neuropharmacology, 21: 663-669.

12. Becker JB, Beer ME \& Robinson TE (1984). Striatal dopamine release stimulated by amphetamine or potassium: influence of ovarian hormones and the lightdark cycle. Brain Research, 311: 157-160. 